\title{
Assessment of medical doctors adherence to national protocol for treatment of severe pneumonia in under- five children admitted to Wad- Medani pediatric teaching hospital, Gezira State, Sudan (2018)
}

\begin{abstract}
Objective: To assess medical doctors adherence to national protocol for treatment of severe pneumonia in under-five children.

Methods: A descriptive, across-sectional among medical doctors and prospective among children study was conducted in the period from $10-25^{\text {th }}$ of October 2018. Children, less than five years of age admitted and treated for severe pneumonia were enrolled. Medical doctors of consultants, registrars, medical officers and house officers in charge of treating the children were enrolled. A pre-constructed questionnaire was distributed among medical doctors and data collection sheets were filled from patient's admission sheet. The data were organized and analyzed using the SPSS version.

Results: Only 80 (72\%) out of 110 enrolled patients treated by medical doctors according to national pneumonia protocol. Benzylpenicillin was most single used antibiotic followed by cefotaxime while cefepime was least one majority of patients $77(70 \%)$ were responded to treatment $65(59 \%)$ patients' responded that prescribed according to national pneumonia protocol. There was association between adherence to national pneumonia protocol and immunization status of patient's p-value 0.001 , while association was not considered significant between response and the immunization status of patients. The barriers to follow the protocol by medical doctors includes lack of awareness about protocol, mimic seniors and patient factors such as low socio-economic status of families.
\end{abstract}

Conclusion: Encouraging dissemination and hospital-level implementation of the national protocol by posters, workshops and better training of healthcare providers especially the junior doctors and critical review of implementing the protocol in prescriptions.

Keywords: medical doctors, national protocol, severe pneumonia, under five

\section{Introduction}

Sudanese Association of Pediatricians developed a local protocol in an attempt to reduce morbidity and mortality among children, called Management Protocols for Pediatric Emergencies including management of pneumonia in children [1,2]. According to the national protocol treatment of pneumonia, a single or combination of antibiotics should be used as follows; management of infants less than one year, Ampicillin $50-200 \mathrm{mg} / \mathrm{kg}$ divided q12 hours, Gentamycin $2.5 \mathrm{mg} / \mathrm{kg}$ repeated q8-12 hours or Cefotaxime $100-150 \mathrm{mg} / \mathrm{kg}$ divided q8 hours. The Vancomycin 10-15 mg/ $\mathrm{kg}$ considered if suspected Methicillin-Resistant Staphylococcus Aureus (MRSA). For the management of children aged more than one year, benzylpenicillin 100.0-150.0 IU/kg/day, Cefotaxime $100 \mathrm{mg} / \mathrm{kg} / \mathrm{day}$ IV or Ceftriaxone $100 \mathrm{mg} / \mathrm{kg}$ /day IV divided q8 hours [1].

Pneumonia is one of the leading causes of hospital admission and mortality in children under five years old, especially in developing countries $[1,3,4]$. Children are frequently
Nehal AM Musa ${ }^{1 *}$, Huda M Harron ${ }^{2}$ and Maha M.A Maatoug 3

${ }^{1}$ Clinical Pharmacist, Pedatric Teaching Hosptial, Gezira State, Sudan

2University of Gezira and Pediatrician's Consultant at Wadmadni Pediatric Teaching Hospital, Sudan

${ }^{3}$ Department of Clinical Pharmacy and Pharmacy Practice, University of Gezira, Sudan

*Author for correspondence:

nehalahmedmaster@gmail.com 
hospitalized with severe pneumonia to be administered intravenous antibiotic [5]. Antibiotics are one of the most important medicines available to medical doctors for therapeutic interventions in pneumonia management, to be able to prescribe rationally medical doctors must depend on evidencebased guidelines for management of infants and children with severe pneumonia which may have severe consequences as the quality of prescribing decisions $[5,6]$.

The justification from this study, increasing morbidity and mortality rate among under-five children admitted to Wad-Medani Pediatric Teaching Hospital in Gezira State due to severe pneumonia; 592 out of 1028 total number of admission due to pneumonia in 2017 (statistical report from the hospital). This highlights the need to assess adherence to management protocol treatment of severe pneumonia, because implementation of the protocol of the management of pneumonia may decrease morbidity and mortality among children aged less than five years old.

This study aimed to assess medical doctors' adherence to national protocol for treatment of severe pneumonia in fewer than five children admitted to Wad-Medani Pediatric teaching hospital, Gezira State, Sudan (2018). As specific objectives; firstly to identify the types, doses, frequencies, and accuracy of the antibiotics used. Secondly to compare the response to the treatment between the adherences and an empirical antibiotic regimen initially used in the treatment of patients with severe pneumonia at the end of 48 hours of starting antibiotic. Thirdly to determine awareness of medical doctors on national protocol for treatment of severe pneumonia in under-five children. Finally to identify the factors that halted medical doctors to adherence to national protocol for treatment of severe pneumonia in less than five children.

\section{Material and Methods}

A descriptive, a cross-sectional among medical doctors and prospective among children study was conducted at Wad-Medani Pediatric Teaching Hospital in the period from $10-25^{\text {th }}$ of October 2018. Wad-Medani Pediatric Teaching Hospital was established in March 1987 in WadMedani city the capital of Gezira state in central Sudan. It is the main urban children referral hospital in Gezira state with a capacity of 204 beds and a catchment population more than 77000 people representing the children from one day old to 17 years old from Wadmadni city and neighbor areas. The hospital includes outpatient health care setting; emergency and refer clinic and inpatient health care setting with six units, three clinics and 17 wards (statically report from the hospital). This study was conducted at hospital in the respiratory tract infection ward, pneumonia room. All available children of either sex, aged from 2-59 months with definite labeling diagnosis "severe pneumonia" with sign of severe pneumonia at the time of admission from all medical doctors' units and received an antibiotic during the dates under the study were enrolled. Children who have pulmonary Tuberculosis (TB), or have Human Immunodeficiency Virus (HIV) disease excluded from the study. All available medical doctors (consultants, registrars, medical officers, and house officers) were included in the study except who were absent or refuse to participate.

The data were collected using data collection sheet filled by the researcher from the patient's files. The pre-constructed self-administered questionnaire used to assess the awareness and the factors that halted of medical doctors to follow the national protocol for the treatment of severe pneumonia in under-five children. Data collection sheet composed of recorded demographic characteristics, clinical assessment of treatment data as prescribed and written by treating medical doctors at the time of admission and reassessment after 48 hours of starting using antibiotic which based on symptom and clinical signs; symptoms (cough and inability to drink), clinical signs (lower chest wall indrawing, tachypnea; respiratory rate "RR" $\geq$ 50 breaths/minute in children $2-11$ months, RR $\geq 40$ breaths/minute in children $12-59$ months and temperature of $\geq 37.5^{\circ} \mathrm{C}$ [7]. The patient was labeled "responding" if the respiratory rate returned to age-specific normal range, less fever, eating better and disappearance of lower chest wall in drawing after 48 hours following prescription [7]. The patient was labeled "not responding” if respiratory rate did not return to age-specific normal at the end of 48 hours of antibiotic treatment, still febrile and/not eating better and remaining of lower chest wall in drawing [7]. Medical doctors were labeled "adherence" if antibiotics prescribed to the patients according to the national pneumonia protocol [2]. Medical doctors were labelled "non-adherence" if antibiotics not prescribed to the patients according to the national pneumonia protocol [2]. Collected data entered 
into the Statistical Package of Social Sciences (SPSS) version20 and descriptive analysis was conducted. A 95\% Confidence Interval (CI) were calculated and $p$-value $<0.05$ was considered significant. The ethical approval obtained from the ethical committee from University of Gezira and Gezira State Ministry of Health.

\section{Results}

A total of 110 patients were included in the study, $61(55.5 \%)$ males and $49(44.5 \%)$ female. $57(51.8 \%)$ of patients age were more than one year old. Regarding the immunization status of patients, $60(54.5 \%)$ was considered fully immunized according to the Sudan program of immunization.

$104(94.6 \%)$ of the patients were presented with cough which was considered the most frequent symptom followed by fever 101 $(90.2 \%)$, then lower chest wall in drawing $42(47.5 \%)$, while the least one $6(5 \%)$ was diarrhea as illustrated in TABLE 1.

Benzylpenicillin was the most single used antibiotic $62(56.4 \%)$ followed by Cefotaxime $29(26.4 \%)$, while Cefepime was the least one 1 (0.9\%) as shown in FIGURE 1.

A total of $80(72.7 \%)$ patients received benzylpenicillin in this study, $9(8.2 \%)$ patients

\begin{tabular}{|c|c|c|}
\hline TABLE 1. Clinical manifestations of Hospitalized children with Pneumonia. \\
Variable & Total $\mathbf{n = 1 1 0}$ & percentage \\
\hline Cough & 104 & $94.60 \%$ \\
\hline Fever & 101 & $90.20 \%$ \\
\hline Lower chest wall in drawing & 42 & $47.50 \%$ \\
\hline Decrease of breast feeding & 12 & $10.70 \%$ \\
\hline Running nose & 9 & $8 \%$ \\
\hline Vomiting & 7 & $6.30 \%$ \\
\hline Diarrhea & 6 & $5 \%$ \\
\hline
\end{tabular}

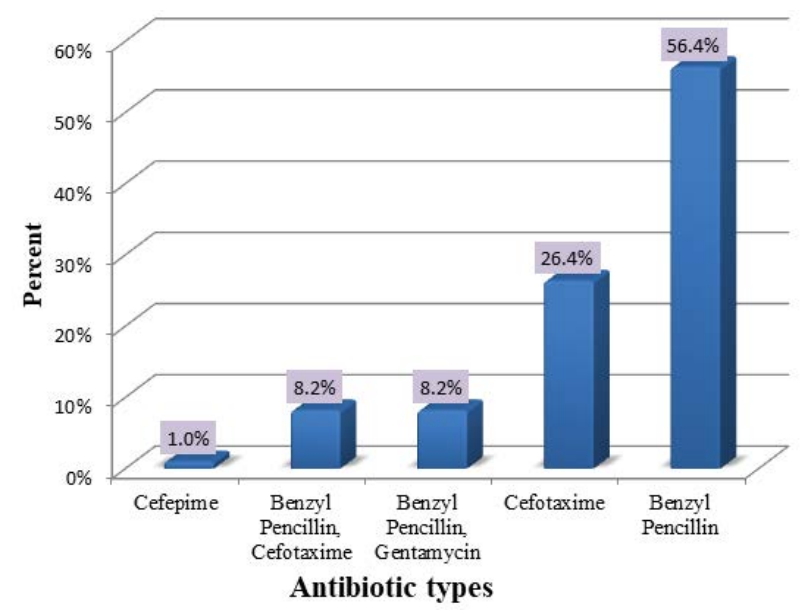

FIGURE 1. Types of Antibiotics used for treatment of severe pneumonia. received Gentamycin in combination with benzylpenicillin and 38 (34.5\%) patients received Cefotaxime as illustrated in TABLE 2.

In the comparison between the received and calculated antibiotic dose, there was no significant difference in mean of gentamycin dose because all doses were accurate (p-value, $0.080)$. There was a significant difference in mean of cefotaxime doses ( $\mathrm{p}$-value, 0.000). There was significant difference in mean of benzylpenicillin doses ( $\mathrm{p}$-value, 0.001) as illustrated in TABLE 3.

A total of $9(100 \%)$ received Gentamycin doses, 54 (67\%) received Benzylpenicillin doses and $19(50 \%)$ of received Cefotaxime doses were accurate in treatment of patients shown in FIGURE 2.

In logistic regression none of the investigated variable (age, gender, and clinical manifestations) was associated with the adherence or patient's response to the national pneumonia protocol. There was association between adherence to national protocol and immunization status of patients, while association was not considered significant between response and immunization status as illustrated in TABLE 4.

Fifty medical doctors responded by (50\%) to the self-administered questionnaire used to assess their awareness and the factors that affect adherence of medical doctors to national protocol for treatment of severe pneumonia in under-five children. Six (12\%) consultants, 12 (24\%) registrars, 12 (24\%) medical officers and $20(40 \%)$ house officers, the majority were females 40 (80\%). Regarding age of physicians that included in this study, majority 38 (76\%) were in the age group (25-30 years) and mean of experiences two years (TABLE 5).

Majority of medical doctors $40 \quad(80 \%)$ followed the national protocol in the treatment of severe pneumonia. 100\% consultants and registrars were aware of the national protocol while, $25 \%$ of medical officers and $50 \%$ of house officers weren't aware of the national protocol; most of house officer didn't have this protocol. $15(30 \%)$ of physicians had national protocol in soft format, followed by $8(16 \%)$ who had in hard format while 24 (46\%) didn't have the protocol as illustrated in TABLE 6.

Regarding patients' response after 48 hours from starting antibiotic, $80(72 \%)$ of patients treated were according to national pneumonia protocol. $77(70 \%)$ of patients responded to 
TABLE 2. Distribution of study patients according to the calculation of received antibiotics dose/frequency.

\begin{tabular}{|c|c|c|c|}
\hline Antibiotics & Received dose/frequency Total $\mathbf{n}(\%)$ & Right doses & Wrong doses \\
\hline Benzyl penicillin & $80(72.20 \%)$ & $54(67.50 \%)$ & $26(32.50 \%)$ \\
\hline 0.25 IU/6 hours & $15(18.75 \%)$ & $11(73.33 \%)$ & $4(26.67 \%)$ \\
\hline 0.5 IU/6 hours & $22(27.50 \%)$ & $18(81.82 \%)$ & $4(18.28 \%)$ \\
\hline 1 IU/6 hours & $43(53.75 \%)$ & $25(58.14 \%)$ & $18(41.86 \%)$ \\
\hline Gentamycin & $9(8.20 \%)$ & $9(100 \%)$ & $0(0 \%)$ \\
\hline$>10 \mathrm{mg} / 8$ hours & $1(11.11 \%)$ & $1(100 \%)$ & $0(0 \%)$ \\
\hline $10-12.5 \mathrm{mg} / 8$ hours & $3(33.33 \%)$ & $3(100 \%)$ & $0(0 \%)$ \\
\hline$<12.5 \mathrm{mg} / 8$ hours & $5(55.55 \%)$ & $5(100 \%)$ & $0(0 \%)$ \\
\hline Cefotaxime & $38(34.50 \%)$ & $19(50 \%)$ & $19(50 \%)$ \\
\hline$>125 \mathrm{mg} / 6-8$ hours & $5(13.15 \%)$ & $2(40 \%)$ & $3(60 \%)$ \\
\hline $125-250 \mathrm{mg} / 6-8$ hours & $29(76.32 \%)$ & $16(55.17 \%)$ & $13(44.83 \%)$ \\
\hline$<250 \mathrm{mg} / 6-8$ hours & $4(10.53 \%)$ & $1(25 \%)$ & $3(75 \%)$ \\
\hline
\end{tabular}

TABLE 3. Comparatives between received and accurate antibiotics doses.

\section{Antibiotics}

\section{Total}

Benzyl penicillin (IU)

Received

Calculated

\begin{tabular}{|l|l|l|}
\hline 80 & 0.6 & 0.5 \\
\hline 80 & 0.72 & 1 \\
\hline
\end{tabular}

Median

Dose accuracy

\section{Gentamycin (mg)}

Received

Calculated

\begin{tabular}{|l|l|l|}
\hline 9 & 10.4 & 10 \\
\hline 9 & 10.4 & 10 \\
\hline
\end{tabular}

St. deviation

$4(26.67 \%)$

$4(18.28 \%)$

\section{Cefotaxime (mg)}

Received

Calculated

\begin{tabular}{|l|l}
38 & 208.1 \\
\hline 38 & 200.3
\end{tabular}

\begin{tabular}{|l|l|l}
208.1 & 200 & 101.6
\end{tabular}

0.27

0.31

\begin{tabular}{|l|l|}
\hline 0.25 & 1 \\
\hline 0.25 & 1 \\
\hline
\end{tabular}

\section{p-value}

t-test for equality of means; $p$-value less than 0.05 significant

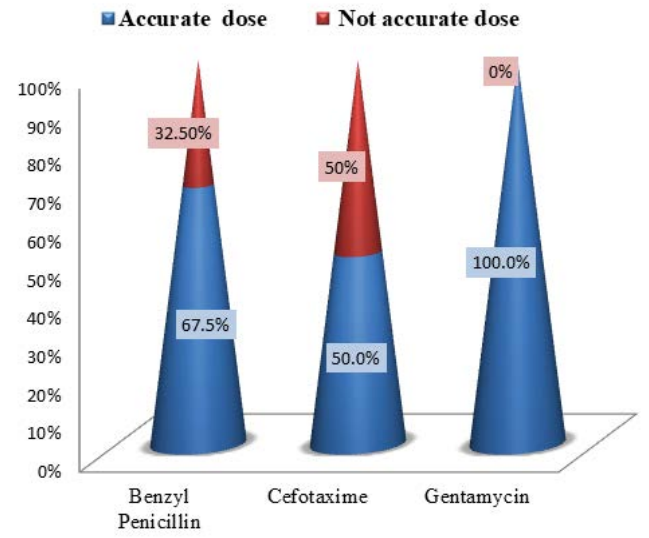

FIGURE 2. Distribution of patients according to accuracy of antibiotic dose.

TABLE 4. Multivariables association regarding patient's demographic data and basic characteristics.

\begin{tabular}{|c|c|c|c|}
\hline Variable & $\begin{array}{c}\text { Antibiotic } \\
\text { used }\end{array}$ & Response & Adherence \\
\hline Gender & 0.228 & 0.769 & 0.06 \\
\hline Age & 0.228 & 0.769 & 0.06 \\
\hline $\begin{array}{c}\text { Immunization } \\
\text { status }\end{array}$ & 0.01 & 0.095 & 0.001 \\
\hline $\begin{array}{c}\text { Clinical } \\
\text { manifestations }\end{array}$ & 0.982 & 0.207 & 0.314 \\
\hline p-value less than 0.05 significant \\
\hline \multicolumn{4}{|l}{} \\
\hline \multicolumn{4}{|l}{} \\
\hline
\end{tabular}

\begin{tabular}{|c|c|c|}
\hline Characteristic & frequencies Total n (50) & percentage \\
\hline \multicolumn{3}{|c|}{ Gender } \\
\hline Male & 10 & 20 \\
\hline Female & 40 & 80 \\
\hline \multicolumn{3}{|c|}{ Specialties } \\
\hline consultants & 6 & 12 \\
\hline Registrars & 12 & 24 \\
\hline Medical officers & 12 & 24 \\
\hline House officers & 20 & 40 \\
\hline \multicolumn{3}{|c|}{ Age/Years } \\
\hline$>25$ & 1 & 2 \\
\hline $25-30$ & 38 & 76 \\
\hline $30-35$ & 7 & 14 \\
\hline$>35$ & 4 & 8 \\
\hline \multicolumn{3}{|c|}{ Years of Experience } \\
\hline$>1$ & 31 & 62 \\
\hline 01-May & 13 & 26 \\
\hline 06-Oct & 5 & 10 \\
\hline$>10$ & 1 & 2 \\
\hline
\end{tabular}

treatment. 65(59\%) patients' responded that prescribed according to national pneumonia protocol as illustrated in TABLE 7.

Regarding factors that halted medical doctors to adhere to national protocol, more than half of physicians 16 (53.4\%) declared that they lack awareness about protocol, 9 (30\%) of physicians 
TABLE 6. Association between job specialties and adherence to protocols.

\begin{tabular}{|c|c|c|c|c|c|}
\hline \multirow[t]{2}{*}{ Characteristic } & \multicolumn{4}{|c|}{ Job Specialties } & \multirow[t]{2}{*}{ p-value } \\
\hline & Consultant & Registrars & Medical officer & House officer & \\
\hline \multicolumn{6}{|l|}{ Adherence to guidelines } \\
\hline \multirow[t]{2}{*}{ National } & $5(83.3 \%)$ & $9(75 \%)$ & $9(75 \%)$ & $17(85 \%)$ & 0.866 \\
\hline & $1(16.7 \%)$ & $3(25 \%)$ & $3(25 \%)$ & $3(15 \%)$ & \\
\hline \multicolumn{6}{|c|}{ Awareness about Sudan pediatric association protocol } \\
\hline Yes & $6(100 \%)$ & $12(100 \%)$ & $9(75 \%)$ & $10(50)$ & 0.006 \\
\hline No & $0(0 \%)$ & $0(0 \%)$ & $3(25 \%)$ & $10(50 \%)$ & \\
\hline \multicolumn{6}{|l|}{ Had the protocol } \\
\hline Yes & $6(100 \%)$ & $11(91.6 \%)$ & $5(41.7 \%)$ & $4(20 \%)$ & 0.001 \\
\hline No & $0(0 \%)$ & $1(8.3 \%)$ & $7(58.3 \%)$ & $16(80 \%)$ & \\
\hline \multicolumn{6}{|l|}{ Type of the protocol } \\
\hline Soft & $2(33.3 \%)$ & $10(83.3 \%)$ & $2(16.7 \%)$ & $1(5 \%)$ & 0.07 \\
\hline Hard & $3(50 \%)$ & 1 (8.3\%) & 1 (8.3\%) & $3(15 \%)$ & \\
\hline
\end{tabular}

\begin{tabular}{|c|c|c|c|c|}
\hline TABLE 7. Association between Patients' response to treatment and Physicians' adherence to treatment protocol. \\
\hline Characteristics & Adherence to treatment according to protocol & Total & p-value \\
\hline & adhere & $12(11 \%)$ & $77(70 \%)$ & 0.001 \\
\hline Patients' responded & $65(59 \%)$ & $18(16 \%)$ & $33(30 \%)$ & $110(100 \%)$ \\
\hline Patients' non responded & $15(14 \%)$ & $30(28 \%)$ & \\
\hline Total & $80(72 \%)$ & & \\
\hline
\end{tabular}

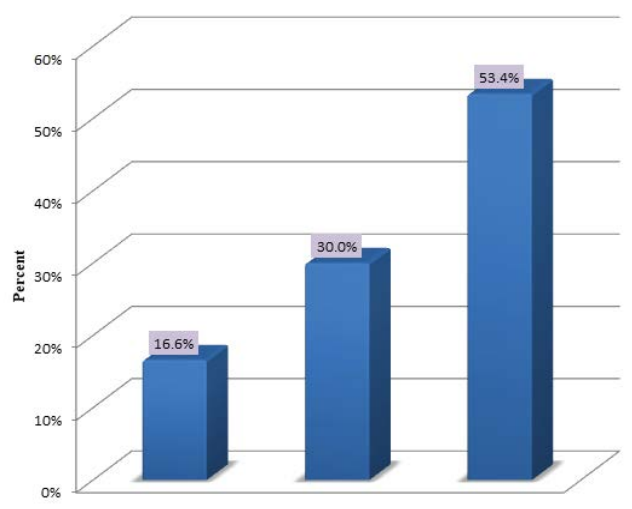

FIGURE 3. Distribution of medical doctors according to factors that halted to adhere to national protocol.

deviated from the protocol in the context of a patient's unique situation which includes, limited financial resource of parents, while only $5(16.6 \%)$ of physicians follow their senior doctors as illustrated in FIGURE 3.

\section{Discussion}

This study showed that, more than half of patients involved in the study were males, the gender distribution indicated that pneumonia was more prevalent in male children than in female children, in the United Kingdom, a case-control study found that pneumonia was more prevalent in male [8], also this finding agrees with the Sudanese study done by Gritly
SM, et al. [9] which found pneumonia occurs more commonly in males than females. More than half of patients aged more than one year old this finding disagrees with the study of Gritly SM, et al. [9] were found most of the patients less than one year old of age, which was significant $(p<0.005)$ because this age group develop severe illnesses like severe pneumonia, with the consequences of increasing morbidity and mortality.

This study demonstrated more than half of patients were considered fully immunized according to the Sudan program of immunization schedule; the others did not complete immunization due to their young age. The patients' response had no association with the immunization status, which agree with Bangladesh study [3].

Injectable antibiotics were used in the treatment of severe pneumonia, this finding agrees with WHO, American and Sudanese guideline $[2,3,10]$. After hospital admission, both single and a combination of double antibiotics were used, Benzylpenicillin was the most single used antibiotic followed by Cefotaxime, while Cefepime was the least one. Gentamycin used in combination with benzylpenicillin, this result indicated there was appropriate usage of antibiotics as recommended by the WHO, American and 
Sudanese guideline, although the inappropriate antibiotic use for pneumonia treatment remain common in other settings [11]. In Bangladesh study, there was inappropriate use of highergeneration cephalosporin and carbapenem which were noncompliance with the WHO guidelines [3]. In another Tanzanian study, 50\% of the children with severe pneumonia were treated with antibiotics not recommended by the WHO [12].

This study revealed that, all of received Gentamycin doses, $67 \%$ received Benzylpenicillin doses and $50 \%$ of received Cefotaxime doses were accurate in treatment of patients, this result need contribution of clinical pharmacist clinical knowledge and silks which help in developing a pharmaceutical care plan, answering medication information queries that may reduce the dosing errors.

The main finding in this study is $80(72 \%)$ adherence to the National Pneumonia Protocol. In a Kenyan survey poor guideline adherence was attributed to preferences for broader spectrum, non-beta-lactam antibiotics [13]. Majority of patients $77(70 \%)$ responded to treatment, 65 (59\%) responded to prescribing according to the protocol, this result indicated strong relationship between response and adherence to protocol (p-value 0.001). In a Sudanese study there was no difference in response between adherence and non-adherence [1]. In logistic regression none of the investigated variable (age, gender, and clinical manifestations) was associated with the adherence or patient's response to the national pneumonia protocol.

This study showed that, most of the medical doctors, followed the national pneumonia protocol, all consultants and registrars have a knowledge about the national protocol by the Sudan Association of pediatricians, while one third of medical officers and half of house officers didn't have a knowledge about the national protocol, this result indicated there was strong relationship between the job specialties and the awareness to the protocol ( $\mathrm{p}$-value 0.006). In American study, age of practitioners and experience were more strongly influenced their adherence to protocols and guidelines [5].

The main primary barriers to adopt the protocols include awareness, familiarity, and agreement with the contents [5]. In this study lack of awareness was the main barrier to follow the protocols especially in junior doctors. A Kenyan study reported a lower rate $(48.3 \%)$ among doctor treating children with pneumonia in which prescription had improved to $90 \%$ adherence after training of health providers and intervention of booklet distribution [14], these praises training as an important tool in improving adherence and thus better outcome of pneumonia treatment in children. Secondly, junior doctors who were oriented about the protocol only mimic senior and didn't read the protocol. Thirdly, the patient's factors include, limited financial resource of parents; physician's prescribing habits are influenced by personal income generated [5]. The two studies carried out at Omdurman Pediatric Hospital and Mohamed Al-Amin Hamid Pediatric Hospital at Khartoum State, Omdurman Locality, about childhood pneumonia, showed that most of the patients were of low socioeconomic class families $[9,15]$.

This study did not address the antibiotic received before the hospitalization, the supportive management during the hospitalization and long term outcome of children such as mortality. In addition to the effort of health system and family factors that may influence the implementation of the national protocols.

\section{Conclusion}

$80(72 \%)$ of patients treated according to the national protocol for treatment of severe pneumonia in under-five children admitted to Wad-Medani Pediatric Teaching Hospital. There was an appropriate use of narrow-spectrum antibiotics (Benzylpenicillin, Cefotaxime, and Gentamycin) for treatment of severe pneumonia as recommended by the WHO, American and Sudanese guideline. The response of children treated according to protocol was more than those who were not treated according to protocol. There was strong relationship between the job specialties and the awareness of the protocol. The barriers to follow the protocols include poor awareness of physicians about the protocol, mimic seniors and patients factors which include; limited financial resource of parents.

\section{Competing Interest}

Authors declare that they have no conflict of interest.

\section{Author Contributions}

Huda M Harron and Maha Mirghani have read the manuscript to revise it carefully and have approved the final manuscript. 


\section{Acknowledgement}

The author would like to thank first my God Allah, and express my deep senses of gratitude to my family for supporting and encouraging. I am very thankful to the family of Al-Shaheed pharmacy also thanks medical doctors, children and their parents who participated in this study. 


\section{REFERENCES}

Salih KE, Bilal JA, Alfadeel MA, et al. Poor adherence to the World Health Organization guidelines of treatment of severe pneumonia in children at Khartoum, Sudan. BMC Res Notes. 7, 531 (2014).

Salih MAM, Satti SA, Swar MO. Building civilization starts from childhood. Sudan J Paediatr. 13, 6-10 (2013).

Rashid MM, Chisti MJ, Akter D, et al. Antibiotic use for pneumonia among children under-five at a pediatric hospital in Dhaka city, Bangladesh. Patient Prefer Adherence. 11, 13351342 (2017).

Wardlaw TM, Johansson EW, Hodge MJ. Pneumonia: The forgotten killer of children. UNICEF. 40 (2006).

Phuong NTK, Hoang TT, Van PH, et al. Encouraging rational antibiotic use in childhood pneumonia: a focus on Vietnam and the Western Pacific Region. Pneumonia (Nathan). 9, 7 (2017).

Mathur S, Fuchs A, Bielicki J, et al. Antibiotic use for community-acquired pneumonia in neonates and children: WHO evidence review. Paediatr Int Child Health. 38, 66-75 (2018).

da Fonseca Lima EJ, Lima DEP, Serra $\mathrm{GHC}$, et al. Prescription of antibiotics in community-acquired pneumonia in children: are we following the recommendations? Ther Clin Risk Manag. 12, 983-988 (2016).

Mahalanabis D, Gupta S, Paul D, et al. Risk factors for pneumonia in infants and young children and the role of solid fuel for cooking: A case-control study. Epidemiol Infect. 129, 65-71 (2002).

Gritly SM, Elamin MO, Rahimtullah H, et al. Risk factors of pneumonia among children under 5 Years at a pediatric hospital in Sudan. Int J of Medl Res Health Sci. 7, 60-68 (2018).

Bradley JS, Byington CL, Shah SS, et al. The management of community-acquired pneumonia in infants and children older than 3 months of age: Clinical practice guidelines by the pediatric infectious diseases society and the Infectious Diseases Society of America. Clin Infect Dis. 53, 25-76 (2011).

Kibuule D, Kagoya HR, Godman B.
Antibiotic use in acute respiratory infections in under-fives in Uganda: findings and implications. Expert Rev Anti Infect Ther. 14, 863-872 (2016).

Gwimile JJ, Shekalaghe SA, Kapanda $\mathrm{GN}$, et al. Antibiotic prescribing practice in management of cough and/or diarrhea in Moshi municipality, Northern Tanzania: crosssectional descriptive study. Pan Afr Med J. 12, 103 (2012).

Calverton M. National Institute of Population Research and Training (NIPORT). Mitra and Associate and ORC Macro. (2005).

Irimu GW, Gathara D, Zurovac D, et al. Performance of health workers in the management of seriously sick children at a Kenyan tertiary hospital: before and after a training intervention. PloS One. 7, e39964 (2012).

Salih KE, Salih A, El Fatih Z, et al. Characteristics associated with severe pneumonia in under-five children admitted to emergency units of two teaching hospitals in Khartoum, Sudan. Sudan J Paediatr. 11, 25-31 (2011). 